\title{
Choderlos De Laclos, Les Liaisons dangereuses
}

\section{Franco Piva}

\section{(2) OpenEdition}

\section{Journals}

\section{Édition électronique}

URL : https://journals.openedition.org/studifrancesi/40822

DOI : 10.4000/studifrancesi.40822

ISSN : 2427-5856

\section{Éditeur}

Rosenberg \& Sellier

\section{Édition imprimée}

Date de publication : 1 juillet 2004

Pagination : 202

ISSN : 0039-2944

\section{Référence électronique}

Franco Piva, «Choderlos De Laclos, Les Liaisons dangereuses », Studi Francesi [En ligne], 142 (XLVIII | I) | 2004, mis en ligne le 30 novembre 2015, consulté le 09 septembre 2021. URL : http://

journals.openedition.org/studifrancesi/40822 ; DOI : https://doi.org/10.4000/studifrancesi.40822

Ce document a été généré automatiquement le 9 septembre 2021.

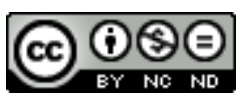

Studi Francesi è distribuita con Licenza Creative Commons Attribuzione - Non commerciale - Non opere derivate 4.0 Internazionale. 


\title{
Choderlos De Laclos, Les Liaisons dangereuses
}

\author{
Franco Piva
}

\section{RÉFÉRENCE}

CHODERLOS DE LACLOS, Les Liaisons dangereuses. Préface, notes et dossier par MICHEL DELON, Paris, Librairie Générale Française, 2002 («Le Livre de poche classique», 354), pp. 573.

Dans sa Préface Michel Delon tente, après bien d'autres, de comprendre et faire comprendre pourquoi une oeuvre qui «a été lue en 1782 comme un simple prétexte à scandale», est devenue "deux siècles plus tard, un ouvrage canonique en France, et l'argument de plusieurs adaptations dramatiques et cinématographiques à travers le monde». Certes, il analyse, comme bien d'autres avant lui, les différentes aspects du roman, de la complexe forme épistolaire à laquelle Laclos a eu recours aux rapports que les personnages ont avec une société qu'on sent à bout de souffle, du langage extrêmement raffiné utilisé par l'auteur pour les caractériser à la géométrie qui règle les rapports des différents personnages. Mais Michel Delon est surtout sensible au succès que l'oeuvre de Laclos a connu ces dernières années, et dont témoignent non seulement les fréquentes rééditions mais aussi des adaptations cinématographiques et des imitations, romanesques ou théâtrales, qu'elle a suscitées ces dernières années et qui en ont, à vrai dire, souvent détourné, du moins partiellement, le sens. «Le tournant $\mathrm{du} \mathrm{XX}^{\mathrm{e}}$ au $\mathrm{XXI}^{\mathrm{e}}$ siècle est fasciné par un roman qui, tout à la fois, lui ressemble trop et lui est profondément étranger» fait remarquer Delon qui explique: «Notre époque lui ressemble par ses interrogations sur le rôle des deux sexes, par la concurrence des modèles du couple fusionnel et de ce que les sociologues nomment désormais le couple fissionnel. Elle lui est étrangère par son oubli de la rhétorique classique, par sa crainte de trop d'intelligience et de contrôle formel. Notre plaisir à lire et à relire Laclos vient de ce mélange de familiarité et d'étrangeté». Est-ce à dire que la réponse à laquelle la Préface a tenté de répondre est, finalement, plus simple qu'on ne l'avait pensé? Ce n'est pas sûr, d'autant plus que cette perspective risquerait d'appauvrir à l'excès un texte 
dont l'analyse de Michel Delon a, au contraire, laissé entrevoir l'extrême richesse, mais elle peut nous aider à comprendre l'étrange fascination que ce livre continue d'exercer sur l'intelligence et la conscience non seulement des gens du métier mais aussi du lecteur normal, jeune aussi bien que âgé. 